\title{
A New Baccalaureate Program in Wireless Engineering
}

\author{
Victor P. Nelson ${ }^{1}$, Richard O. Chapman ${ }^{2}$, Richard C. Jaeger ${ }^{1}$ \\ Auburn University, Alabama \\ 1. Department of Electrical and Computer Engineering \\ 2. Department of Computer Science and Software Engineering
}

\begin{abstract}
The first baccalaureate program in Wireless Engineering in the U.S. was initiated within the Samuel Ginn College of Engineering of Auburn University in the Fall Semester of 2002. This new program has been designed to meet the needs of telecommunications companies, wireless network service providers, manufacturers of telecommunication network switching equipment, wireless application developers, and manufacturers of personal wireless communication appliances, such as telephones and personal digital assistants. Graduates of this program will be prepared to work on emerging and future wireless communications applications such as third- and fourth-generation (3G and $4 \mathrm{G}$ ) cellular telephony, broadband wireless local loop, high-speed wireless local area networks, mobile Internet access, wireless information appliances, and supporting telecommunications network infrastructure.
\end{abstract}

\section{Introduction}

The new Wireless Engineering Program in the Auburn University Samuel Ginn College of Engineering is a joint offering of the Department of Electrical and Computer Engineering (ECE) and the Department of Computer Science and Software Engineering (CSSE), leading to the Bachelor of Wireless Engineering (BWE) degree. It is an interdisciplinary venture that blends the expertise and strengths of faculty and programs from ECE and CSSE. Building on traditional broad-based programs in these departments, the BWE program has been designed to provide the knowledge and skills required to practice engineering in the wireless telecommunications industry in these times of a mobile society. Graduates of this program will be able to analyze, design, test, administer and support wireless network systems, software, communication devices, and other components used in wireless computer and telecommunication networks. Examples of businesses who are interested in these graduates include wireless network service providers, manufacturers of telecommunication network switching equipment, wireless application developers, and manufacturers of personal wireless communication appliances, such as telephones and personal digital assistants.

Because the engineering needs of these businesses vary over a wide range, the BWE program offers two options: Wireless Electrical Engineering (Wireless EE), emphasizing the design of hardware and networks for the wireless industry, and Wireless Software Engineering (Wireless SWE), emphasizing the design of software and networks for the wireless industry. Each is based on undergraduate electrical/software engineering 
fundamentals, and builds on these to introduce wireless communications theories, devices, circuits, systems, networks, standards, management, and applications.

\section{Bachelor of Wireless Engineering Program}

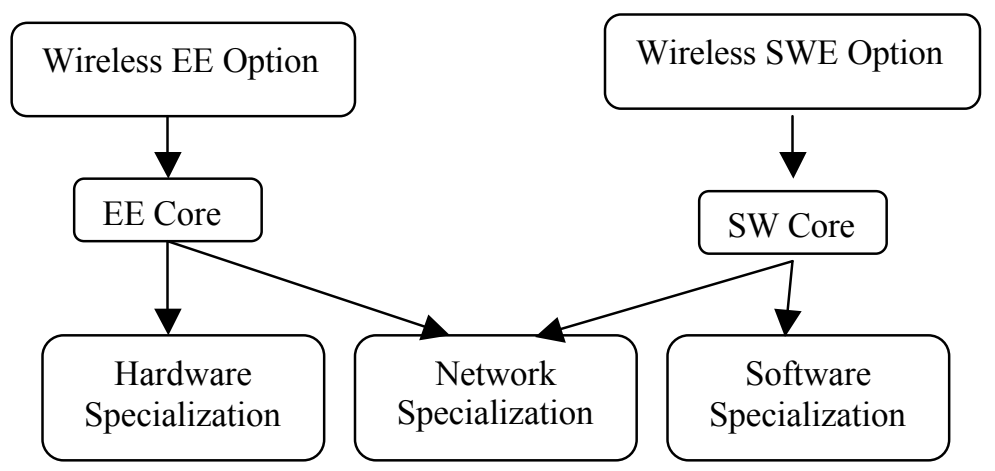

Through a choice of several courses within the senior year, a student selects one of two areas of specialization within each degree option. Students interested in designing wireless hardware, such as integrated circuits, hand-held wireless communication devices, and wireless switching equipment, will choose the Hardware Specialization within the Wireless EE Option. Students interested in application development, including server-side as well as client-side, and embedded applications, will choose the Software Specialization within the Wireless SWE Option. Both options provide a Network Specialization for those students interested in pursuing a career with wireless service providers and other telecommunications companies (those companies that develop and maintain wireless networks and sell service). This specialization will prepare students to analyze, develop, design, test, administrate and support wireless network systems, and to integrate products from various vendors into new or existing networks.

Each curriculum builds upon a solid foundation in mathematics, science, and electrical or software engineering fundamentals to introduce wireless communications theories, devices, circuits, systems, networks, standards, management, and applications. Design experience is interwoven throughout the curriculum by introducing basic design concepts early, emphasizing hands-on design experiences in the laboratories, including effective use of computers and other modern engineering tools, and culminating with a capstone design project in the senior year. In addition to its technical aspects, the curriculum emphasizes oral and written communication skills, the importance of business, economic, social and global forces on engineering, appreciation of the need to maintain the highest ethical standards, and the maintenance of professional competence through continued self-improvement after graduation.

\section{Motivation for Creating the BWE Program}

The wireless industry has undergone dramatic growth in the past decade. This field has expanded from a few simple short-range devices to global wireless networks linking a wide variety of hand-held and other communicating devices, such as cellular telephones with Internet and email capability, personal digital assistants, notebook and desktop computers, global positioning systems, medical monitors, and more. Wireless devices 
are proliferating and expanding in capability to work with voice, video, and data, while becoming more personal and portable. Networks of these devices are becoming more complex to design and manage effectively, and integrate with existing telecommunications networks. This all results in many new engineering problems to be solved. There already exists a critical shortage in industry for RF/wireless circuit, software, system, and network designers, and this shortage is expected to increase over the next two decades.

This need was emphasized in 2001, when the Auburn University College of Engineering received a \$25 million gift from Dr. Samuel Ginn, retired chairman of Vodafone AirTouch Plc. The income from the endowment created with this gift has been earmarked to support the development of undergraduate and graduate programs within the College of Engineering to address the education of engineers to work in the wireless telecommunications industry.

The current undergraduate Electrical Engineering (EE) and Software Engineering (SWE) curricula at Auburn University are designed to prepare students to work in a wide range of industries, giving them a broad base upon which they can build, with subsequent education and training, to meet industry-specific needs. The rapidly-growing wireless telecommunications and related industries require engineers with knowledge of RF (radio frequency) electronics, wireless communication theory, telecommunications networks, and wireless system and application software. While these topics may be covered in traditional EE and SWE curricula, in many cases as elective courses offered late in the program or as graduate courses, they are the bread and butter of wireless engineers. These courses must be taken earlier, required of all majors, and used as the foundation upon which other more advanced wireless courses can build. Thus, while many traditional EE programs, and even some CS programs, offer an elective or two in networks or RF design, it is difficult for a student in those programs to acquire the skills needed to design, build and operate today's wireless communications devices and networks.

\section{The Program Development Process}

In the spring of 2001, the Wireless Education and Research Center (WEREC) was established in the College of Engineering to support the development of a comprehensive program of education, research, and extension activities in wireless engineering at both the undergraduate and graduate levels. Preliminary wireless engineering program proposals $\mathrm{w}$ ere developed by WEREC faculty as formal options within the B.E.E. (Bachelor of Electrical Engineering) and B.Sw.E. (Bachelor of Software Engineering) programs. In summer of 2001, a joint ECE/CSSE committee met to consolidate these proposals into a single B.W.E. program with two options - Wireless Electrical Engineering and Wireless Software Engineering.

To provide guidance in both the initial and ongoing development of both the BWE program and related programs, the WEREC Advisory Board was created in the fall of 
2001. The board consists of top technical officers from a number of prominent companies representing the different segments of the wireless industry, including Vodafone, Nortel Networks, Verizon Wireless, Ericcson, Nokia Mobile Phones, Texas Instruments, Hewlett-Packard, and Cingular Wireless. These industry leaders meet twice annually with WEREC faculty to discuss WEREC activities and to offer suggestions, advice, and assistance. A number of the board companies have also hosted visits by Auburn faculty to help provide a better understanding of the requirements of the wireless industry. One outcome of this interaction was the addition of the networking "specializations" to the initial BWE curriculum proposal to support wireless service providers and related telecommunications companies, whose needs vary significantly from those of wireless equipment manufacturers.

\section{The BWE Curriculum}

A summary of the BWE curriculum is given in the Appendix. The undergraduate EE and SWE curricula formed the starting points for the Wireless EE and Wireless SWE Options, respectively. This includes the university core, math, science, and engineering support courses common to all programs in the ECE and CSSE departments.

The two departments had previously offered a number of wireless courses. These were supplemented by a number of new courses developed specifically for this program. The EE curriculum already included courses in circuits, digital systems, electronics, electromagnetics, and communication systems. To these were added courses in wireless communication theory and wireless networks, along with a new wireless communications lab, in which students in the Wireless EE Option will team with students from the Wireless SWE Option. Students in the two options will also team up in most of the capstone design projects. For the "hardware design" specialization, courses in RF devices and circuits and digital signal processing are specified. For the "network design" specialization, students take courses in data networks, telecommunications networks, and network optimization.

The Wireless SWE curriculum was created by replacing courses in operating systems and software design, targeted more at "large systems", with comparable courses focusing on embedded systems, as are used in wireless applications. To provide the necessary background in communication theory, the EE course sequence leading up to and including the communications systems course and the wireless communications lab were added to the curriculum. In addition, students take courses in both wireless networks and data networks. For the "software design" specialization, courses in software engineering and quality assurance are specified, For the "network design" specialization, students take courses in telecommunications networks, network optimization, and network quality assurance.

\section{Current Status of the BWE Program}

In the winter and spring of 2002, the BWE program received formal approval of the Wireless Technical Advisory Board, the Auburn University Board of Trustees, and the 
Alabama Commission on Higher Education. The program began admitting freshmen and transfer students in Fall Semester of 2002, with the first graduates expected in 2004.

The BWE curriculum has been designed to satisfy the general criteria of the Accreditation Board for Engineering and Technology (ABET) "Engineering Criteria 2000" (EC2000), and initial accreditation will be sought as a "unique program". As more universities develop similar programs, Auburn University intends to take a lead role in the development of accreditation criteria specific to wireless engineering.

Auburn University is also active in the Global Wireless Education Consortium (GWEC), a collaboration of wireless industry companies and educational institutions. Through GWEC, Auburn University will share its expertise and developments in wireless engineering education and research with GWEC industrial and academic partners and learn from the contributions of these partners.

Further information on the BWE program and related activities is available on the WEREC web site (http://www.eng.auburn.edu/center/wireless). 


\section{Appendix - Summary of BWE Degree Requirements}

\section{A.U. Core Curriculum ( 30 hours plus math/science below)}

- ENGL1100,1120 (6 hours) - Composition

- ENGL2200,2210 (6 hours) - Literature

- History sequence (6 hours)

- Core Social Science (6 hours)

- PHIL1040 (3 hours) - Philosophy (Business Ethics)

- Fine Arts Elective (3 hours)

Math/Science (32/33 hours, including 12 hours of A.U. core)

- MATH 1610,1620,2630 (12 hours) - Calculus I,II,III

- MATH 2650,2660 (6 hours) - Differential Equations and Linear Algebra

- PHYS1600,1610 (8) - Physics I \& II

- CHEM1030,1031 (4 hours) - Chemistry [Wireless EE Option] or COMP3240 (3 hours) - Discrete Structures [Wireless SWE Option]

- COMP6330 (3 hours) - Network Optimization \& Algorithms [Network Specialization - both options]

or Math/Science Elective (3 hours)

[Wireless EE Hardware Specialization, Wireless SWE Software Specialization]

Free Elective (3 hours)

General Engineering (5 hours)

- ENGR1100,1110 Intro to Engineering (2 hours)

- INSY3600 Engineering Economics (3 hours)

Courses in Major Common to Both Wireless Degree Options (28 hours)

- COMP 1200 (2) - Intro. To Programming

- ELEC 2200, ELEC 2220/COMP 3350 (6) - Digital Circuits, Computer Organization

- ELEC 2110, 2120, 2010 (7) - Circuits, Signals \& Systems, Circuits/EE Lab I

- ELEC 3800, 3400 (6) - Probability, Communication Systems

- ELEC 3060 (1) -Wireless Communications Lab

- ELEC 4000/COMP 4710 (3) - Wireless Senior Design Project

- Wireless Technical Elective (3) 


\section{Wireless Electrical Engineering Option - Courses in Major (23 hours)}

- COMP 3000 (3) - Object Oriented Programming

- $\quad$ ELEC 2210, 3700 (6) - Digital Electronics, Analog Electronics

- ELEC 3310, 3320 (6) - Electromagnetics - Fundamentals/Wireless Applications

- $\quad$ ELEC 2020, 3030 (2) - EE labs (circuits, radio)

- ELEC 6100, 6110 (6) - Wireless Communication Theory, Wireless Networks

\section{Wireless EE Hardware Specialization}

- ELEC 6720 (3) - RF Electronics \& Circuits

- $\quad$ ELEC 6410 (3) - Digital Signal Processing

\section{Wireless EE Network Specialization}

- $\quad$ ELEC 6120 (3) - Telecommunications Networks

- $\quad$ ELEC 6220 (3) - Information Networks \& Technology

- $\quad$ COMP $6330\left(3^{*}\right)$ - Network Optimization \& Algorithms

* COMP 6330 hours were included in math/science hours above

\section{Wireless Software Engineering Option - Courses in Major (24 hours)}

- COMP 2200,2210,3270 (11) - Computer Science I \& II, Algorithms

- COMP 3510,3710 (6) - Embedded Systems Software, Wireless Software Engineering

- COMP 4320, 6360 (3) - Computer Networks, Wireless \& Mobile Networks

- COMP 4730 (1) - Computer Ethics

\section{Wireless SWE Software Specialization}

- COMP 6700 (3) - Software Process

- COMP 6710 (3) - Software Quality Assurance

\section{Wireless SWE Network Specialization}

- $\quad$ ELEC 6120 (3) - Telecommunications Networks

- COMP 6340 (3) - Network Quality Assurance

- COMP $6330\left(3^{*}\right)$ - Network Optimization \& Algorithms

* COMP 6330 hours were included in math/science hours above 